\title{
De tenuitvoerlegging van de levenslange gevangenis- straf: een paradoxale taak. Een beschouwing vanuit de praktijk van het Nederlandse gevangeniswezen ${ }^{1}$
}

\author{
L. van de Sande
}

\section{Inleiding}

De levenslanggestraften vormen een snel groeiende groep binnen het Nederlandse gevangeniswezen, over wie bovendien diverse hardnekkige misverstanden bestaan. Deze misverstanden hebben er lange tijd toe bijgedragen dat er op geen enkele wijze gericht beleid is gevoerd voor de tenuitvoerlegging van de levenslange straf, ondanks het expliciete verschil met elke andere (tijdelijke) straf. Vanuit het Penitentiair Selectie Centrum ${ }^{2}$ is een jarenlange ervaring opgebouwd met het adviseren over en begeleiden van gedetineerden aan wie een zeer lange of levenslange straf is opgelegd. Vanuit deze expertise is er geregeld aandacht gevraagd voor de bijzondere problematiek van levenslanggestraften, zoals thans bij de veranderingen binnen het gevangeniswezen in het kader van DBM (Detentie en Behandeling op Maat). ${ }^{3}$ Steeds opnieuw blijkt echter dat de groep levenslanggestraften dusdanig klein en dusdanig divers is, dat deze voor beleidsmakers lastig te plaatsen valt. Met name in het huidige klimaat wordt vooral gezocht naar de grote aantallen en de uniformiteit, terwijl de (bejegening van de) levenslanggestrafte gebaat is bij maatwerk en nuance.

1 Dit artikel is een weergave van de voordracht zoals gegeven op 5 oktober 2006 voor het Psychiatrisch-Juridisch Gezelschap 'Lutje P.J.G.', te Groningen. Het is inmiddels ook verschenen in Sancties 2007, afl. 1, p. 6-18.

* Gezondheidszorgpsycholoog, werkzaam binnen het Penitentiair Selectie Centrum.

2 Het Penitentiair Selectie Centrum is een kleinschalige voorziening binnen het gevangeniswezen, gevestigd in Den Haag. Afgezien van een klinische onderzoeksafdeling, waar gedetineerden geobserveerd en psychologisch onderzocht worden, is er van oudsher een taak weggelegd voor het PSC in het volgen van langgestraften. Het PSC beschikt over 24 plaatsen voor observatie en 12 plaatsen voor behandeling binnen detentie.

3 DBM is de nadere uitwerking van het project De Nieuwe Inrichting, waarbij de gehele organisatie van het gevangeniswezen grondig wordt herzien. Er wordt globaal ingedeeld in vier domeinen: preventief, kort verblijvend, lang verblijvend en de zogenaamde Bijzondere Groepen (waar extra zorg of beveiliging vereist is). 
Vooraf moet worden opgemerkt dat levenslange gevangenisstraf uiteraard slechts in de uiterste omstandigheden wordt opgelegd, bij zeer ernstige delicten. Dit artikel wil dan ook op geen enkele wijze suggereren dat levenslanggestraften vooral medelijden verdienen. Het doel is met name om aandacht te vragen voor de, relatief onbekende, praktijk van deze straf.

Hoewel de toename van het aantal opgelegde vonnissen van levenslang bezwaarlijk kan worden aangemerkt als een positieve ontwikkeling lijkt er in één opzicht een voordeel uit te ontspringen: de straf komt meer in beeld. Vanuit diverse invalshoeken begint men zich af te vragen wat de consequenties zijn van de aanwezigheid van deze groep in het gevangeniswezen en in hoeverre het beleid (zowel nu als in de toekomst binnen DBM) adequaat is voor deze groep. Ondanks het feit dat er geen simpele richtlijn is te geven voor de gehele groep van levenslanggestraften zijn er vanuit gedragsdeskundig oogpunt wel degelijk adviezen te formuleren. Deze adviezen bevatten echter een duidelijke paradox: we proberen de levenslanggestraften in (psychische) conditie te houden, maar waarvoor eigenlijk?

\section{Een korte blik op de geschiedenis ${ }^{4}$}

In de jaren ' 70 van de vorige eeuw is er, vanuit de toen geldende visie op detentie, aandacht besteed aan de wijze van tenuitvoerlegging van lange vrijheidsstraffen en het perspectief op resocialisatie. Het Penitentiair Selectie Centrum heeft daarin, als psychologisch observatie- en adviescentrum voor het gevangeniswezen, steeds een centrale rol vervuld.

In 1978 is in dit kader de richtlijn "voor de selectie- en detentiebegeleiding van langgestraften en van tot gevangenisstraf veroordeelden die tevens ter beschikking van de regering zijn gesteld" in werking getreden (7 juni 1978 kenmerk nr. 133/379). Het betreft hier de zogenaamde volgprocedure langgestraften. Deze volgprocedure hield onder andere in dat gedetineerden met een straf van 6 jaar of meer na een derde van hun straf te hebben uitgezeten in het Penitentiair Selectie Centrum klinisch werden onderzocht om te beoordelen op welke wijze de verdere tenuitvoerlegging van de straf kon worden gerealiseerd.

4 Met dank aan Klaas Vaartjes, Hoofd Psychologische Dienst van het PSC voor dit overzicht. 
De omschrijving luidde:

Een gedetineerde die veroordeeld is tot een gevangenisstraf van 6 jaar of meer en zijn detentie in een gevangenis ondergaat wordt omstreeks het tijdstip waarop een derde van zijn totale straftijd is verstreken in principe aan een hernieuwd klinisch psychologisch onderzoek onderworpen, teneinde na te gaan welke resultaten de penitentiaire behandeling heeft gehad, hoe op dat moment de psychische gesteldheid is, welke prognose vanuit penitentiair en reclasseringsoogpunt kan worden gesteld en welke aanbevelingen op grond daarvan kunnen worden gedaan. Daarbij kan gedacht worden aan maatregelen voor de opvang in de betreffende inrichting, overplaatsing naar een andere penitentiaire inrichting, plaatsing in een inrichting voor ter beschikking van de regering gestelden of vervroeging van de datum van (voorwaardelijke) invrijheidstelling via een gratieprocedure.

Het doel van de procedure was derhalve het structureel volgen van de detentiesituatie en het geven van aanwijzingen over de inhoud van de tenuitvoerlegging. De mogelijkheid van gratieverlening was expliciet verwerkt in de vraagstelling die bij het advies overwogen moest worden. Let wel: dit was dus in 1978 toen Nederland in totaal ongeveer 3000 detentieplaatsen telde. Het aandeel van de langgestraften daarin was relatief klein en levenslang was toen nog een buitengewoon zeldzame straf.

Omdat in de praktijk bleek dat op lokaal niveau de volgprocedure steeds minder ging leven is in 1994 bij de start van het programma Werkzame Detentie de doelgroep voor de volgprocedure beperkt. Alleen gedetineerden met een strafrestant na veroordeling van 4 jaar of meer (in de praktijk betekende dit een opgelegde straf van ongeveer 8 jaar of meer) en gedetineerden die naast een straf ter beschikking waren gesteld, werden bij de plaatsing in een gevangenis na veroordeling nog voor advies voorgelegd aan het PSC. Deze beoordeling verliep in beginsel op papier, op basis van de informatie van de inrichting van verblijf. Een en ander sloot aan bij de toenemende professionalisering van de zorg op lokaal niveau, onder meer door het opzetten van een overlegvorm tussen de diverse bij de zorg betrokken disciplines (een ontwikkeling die heeft geresulteerd in de huidige PMO's). ${ }^{5}$ In deze

5 PMO: Psycho Medisch Overleg. In dit overleg komen inrichtingspsycholoog, forensisch psychiater en medische dienst samen om de zorg voor gedetineerden met psychische problematiek af te stemmen. De inrichtingspsycholoog is voorzitter en coördinator van 
periode is er, door de veranderende populatie in het gevangeniswezen, een geleidelijke verschuiving gekomen in het speerpunt van de zorg binnen de inrichting naar de meer acute psychiatrische problematiek. Het feit dat het PMO zich vooral moest richten op het voorkomen van crises en het ondersteunen van personeel in het omgaan met (vaak complexe en zeer bewerkelijke) psychische problematiek ging ten koste van de aandacht voor detentietrajecten en meer langdurige begeleidingscontacten. Sinds 1998 is er aan het 'systematisch volgen' van langgestraften een eind gekomen. De hoge werkbelasting van inrichtingspsychologen, de grote toename van het aantal langgestraften en het steeds verder verdwijnen van mogelijkheden om de detentie in te vullen speelden hierin een rol.

De huidige adviestaken van het PSC omvatten (1) advies bij de zogenaamde primaire selectie (overplaatsing naar een gevangenis na veroordeling in eerste aanleg) van gedetineerden met een straf van 8 jaar of langer, (2) advies bij de plaatsing van gedetineerden met minstens 3 jaar gevangenisstraf + TBS en (3) adviezen over plaatsing of overplaatsing en indicatiestelling voor begeleiding of behandeling op verzoek. De eerste twee categorieen, gebaseerd op dossieronderzoek, dienen vooral ter ondersteuning van de selectiefunctionaris of de afdeling ITZ (Individuele TBS Zaken) van het Ministerie van Justitie. De derde categorie houdt in dat het PSC klinisch psychologisch onderzoek verricht door een gedetineerde op te nemen op de onderzoeksafdeling (KPO). ${ }^{6}$ In zulke gevallen wordt een gedetineerde onder de aandacht van het PSC gebracht door medewerkers van de inrichting van verblijf met het verzoek advies uit te brengen, bijvoorbeeld over invulling van de detentie of behandelmogelijkheden. Door de eerder beschreven ontwikkelingen in het gevangeniswezen (grotere aantallen, meer psychiatrie, verdwijnen volgprocedure) is het echter afhankelijk van de locale situatie (en uiteraard van het functioneren van de betreffende gedetineerde) of (levens-)langgestraften onder de aandacht van het PMO komen. Jaarlijks worden er rond de 90 gedetineerden voor onderzoek opgenomen in het PSC. De gemiddelde opgelegde straf van gedetineerden die worden opgenomen ligt rond de 8 jaar en zeker in de laatste vijf jaar zijn er elk jaar één of meer levenslanggestraften opgenomen geweest.

het overleg, maar iedereen werkt onder zijn eigen (BIG-) beroepsverantwoordelijkheid. Op indicatie worden ook andere disciplines bij het PMO betrokken.

6 Uiteraard is het afhankelijk van de praktische uitvoering van DBM hoe deze procedure in de toekomst zal worden uitgevoerd. Met het invoeren van de domeinen en andere maatregelen van DBM zal het proces van plaatsing en selectie ook veranderen. 


\section{Effecten van langdurige detentie}

Uit jarenlange ervaring in de praktijk van het Penitentiair Selectie Centrum blijkt dat er bepaalde overeenkomsten zijn tussen gedetineerden met een zeer lange tijdelijke straf en levenslang, zowel qua delict als qua aanpassing in detentie. De meest voor de hand liggende overeenkomst tussen zeer lange straffen en levenslang is dat er doorgaans levensdelicten, al dan niet in combinatie met zedendelicten, aan het vonnis ten grondslag liggen. Daarnaast is er een overeenkomst te vinden in het globale verloop van de detentie en de reacties daarop.

In het algemeen kan gesteld worden dat een vrijheidsstraf veel dieper ingrijpt in het dagelijkse leven van de betreffende persoon, in diens omgeving, en in de wijze waarop hij zichzelf waarneemt, naarmate de straf langduriger is. De mogelijkheid om zich te distantiëren van het gevangenissysteem en 'zichzelf te blijven' is sterk gerelateerd aan de duur van het verblijf in dat systeem. Hierbij moet gedacht worden aan het bekende begrip van de 'total institution' zoals gedefinieerd door Goffman. ${ }^{7}$ Een omgeving waarin alles sterk gestructureerd en hiërarchisch is opgezet beperkt de keuzevrijheid van degenen die erbinnen moeten functioneren (ook personeel overigens!) en heeft daarmee invloed op hun gedrag en uiteindelijk zelfs op hun identiteit.

\section{Een eigen dynamiek}

Hoewel er geen wetenschappelijk onderzoek aan ten grondslag ligt, is het vanuit de praktijk mogelijk een proces te beschrijven met fasen die de meeste levenslanggestraften doorlopen. Deze fasen zijn deels gekoppeld aan vaste ijkpunten in de detentie (met name de diverse stappen in het strafproces) maar vloeien deels ook simpelweg voort uit het verstrijken van de tijd. In het kort gaat het om de volgende fasen:

7 E. Goffman, onder andere in 'Asylums, essays on the social situation of mental patients and other inmates', New York, Doubleday, 1961. 
1. Tijdens het strafproces is er vaak sprake van boosheid, verzet, ongeloof en het vasthouden aan de hoop dat het vonnis nog wordt herzien.

2. Na het onherroepelijk worden van het vonnis dringt de realiteit zich op. Een eerste besef van de situatie (wat houdt levenslang in) gaat vaak samen met de hoop op gratie in de toekomst.

3. Het vacuüm in de straf ontstaat wanneer de aanpassing die in eerste instantie is gekozen (copingstrategie) en de praktische invulling (keuze voor een bepaalde gevangenissetting of programma-aanbod) slijtage gaan vertonen.

4. Doorgaans is het onvermijdelijk dat er na een zeer langdurige detentie hospitalisatie optreedt.

Overigens zijn er, afgezien van de overeenkomsten, dusdanig grote verschillen tussen gedetineerden met een zeer lange tijdelijke straf en levenslanggestraften, en zelfs binnen deze groepen, dat een geïndividualiseerde aanpak op zijn plaats is. Het verloop van de beschreven fasen is namelijk sterk afhankelijk van de individuele omstandigheden van de gedetineerde. Zowel de persoonlijkheidskenmerken als de sociaal-maatschappelijke situatie (zoals het hebben van een gezin en familie of ingebed zijn in bijvoorbeeld werk) zijn van invloed op de manier waarop iemand zich aanpast aan zijn situatie en op het moment waarop de verschillende fasen optreden. Uit diverse Canadese onderzoeken ${ }^{8}$ blijkt dat er geen algemene reacties op een (lange) detentie zijn te onderscheiden zonder te corrigeren voor zulke individuele karakteristieken. Gedetineerden met een zeer lange of levenslange straf hebben dan ook net zozeer baat bij een aanpak gericht op de algemene kenmerken als bij aandacht voor hun individuele omstandigheden.

\section{De vier fasen}

Fase 1 wordt vrijwel altijd bepaald door het strafproces. Zolang de rechtsgang nog niet is uitgeput houdt men zich vast aan de hoop op een gunstiger vonnis. Bij vrijwel elke gedetineerde is er een verschil merkbaar tussen de periode waarin het strafproces nog loopt en de periode na het onherroepelijk worden van het vonnis. Zolang er hoop is op een gunstiger straf of zelfs 
vrijspraak richt men zich doorgaans sterk op dat perspectief. Het alledaags functioneren wordt duidelijk beïnvloed door deze onzekerheid en men leeft van de ene juridische (strafprocessuele) stap naar de volgende. Geldt deze observatie al voor 'doorsnee' gedetineerden, des te sterker geldt zij voor mensen die extreme vonnissen boven het hoofd hebben hangen zoals levenslang of lange combinatievonnissen (straf + TBS). Kenmerkende reacties zijn vaak boosheid, strijdlust tegen ervaren onrecht en een weigering (of onvermogen) om verder vooruit te denken dan een zittingsdatum. De omgeving van de gedetineerde speelt hierin vaak ook een rol, door te wijzen op de mogelijkheid dat het "nog goed komt". Niet alleen familie, maar ook advocaten en inrichtingspersoneel gebruiken vaak elke mogelijkheid om een gedetineerde een hart onder de riem te steken en moed in te praten. Op deze manier blijft de indringende werkelijkheid van een zwaar vonnis vaak nog wat op afstand.

Fase 2. Het begin van de tweede fase wordt gemarkeerd door het onherroepelijk worden van het vonnis. Dit is voor de gedetineerde het moment dat de realiteit van het vonnis zich opdringt. De status 'levenslang' moet onder ogen worden gezien; er is geen einddatum om naar toe te leven en geen mogelijkheid tot detentiefasering of verloven in de toekomst. In het verleden was dit tevens het moment dat voor het eerst het Huis van Bewaring werd ingeruild voor het (relatief iets ruimere) regime van de gevangenis. Vooruitlopend op de invoering van DBM is deze scheidslijn echter minder scherp geworden nu gedetineerden reeds na veroordeling in eerste aanleg doorgeplaatst worden naar een gevangenis. Desondanks lijkt het onherroepelijk worden van het vonnis doorgaans de voornaamste markering voor een veranderde beleving van de straf. Door het afronden van de strafzaak is er enerzijds de confrontatie met het gebrek aan perspectief en het besef dat het verblijf in detentie zeer langdurig zal zijn. Anderzijds zijn er prettige bijkomstigheden zoals het geleidelijk luwen van media-aandacht en de mogelijkheid om details rondom de zaak en het delict wat los te laten. Doorgaans wordt er in eerste instantie vooral aandacht besteed aan praktische keuzes voor het invullen van de straf. De gedetineerde zal zoeken naar de mogelijkheden die er zijn binnen het gevangeniswezen om een eerste evenwicht te vinden. Factoren die daarbij een rol spelen zijn de mogelijkheid voor bezoek van familie of vrienden, de behoefte aan zorg of beveiliging en het programma-aanbod binnen de inrichting. Dit laatste zal met de invoering van DBM echter steeds beperkter worden door toenemende uniformisering van dagprogramma's en activiteiten binnen detentie. In deze fase is het zinvol 
om een detentieplan te maken voor de eerstkomende jaren. Niet alleen is er vaak nog de hoop op kansen in de toekomst (zoals gratie) maar ook is de keuze voor een bepaalde inrichting of setting van veel (veranderlijke) factoren afhankelijk. Zo kan het aanbod binnen een inrichting veranderen, maar ook de persoonlijke situatie van de gedetineerde.

Fase 3 omvat de periode waarin de sleur en herhaling hun tol gaan eisen. Het langdurige verblijf in de penitentiaire inrichting (meer dan eens dezelfde afdeling gedurende jaren) leidt vaak tot ongewenste neveneffecten. Enerzijds kunnen gedetineerde en personeel 'op elkaar uitgekeken' raken, wat leidt tot irritaties en cynisme. Anderzijds kan er een situatie ontstaan waarbij de gedetineerde 'vergroeit' met een afdeling, waardoor de grenzen tussen gedetineerde en personeel vervagen. Medegedetineerden behandelen de levenslanggestrafte vaak met een mengeling van respect en afstandelijkheid. Zoals de meeste mensen in de omgeving van de levenslanggestrafte vinden zij het moeilijk om zich een houding te geven: de confrontatie met deze straf relativeert de eigen besognes. Afhankelijk van de opstelling van de levenslanggestrafte en de mate waarin deze zich staande weet te houden, ontstaat bij de omgeving bewondering of juist medelijden. Vrij algemeen is er echter de neiging om zo min mogelijk stil te staan bij de realiteit van het vonnis, als ware het een ernstige ziekte. Het 'vacuüm' waarin de gedetineerde zich bevindt heeft doorgaans ook zijn weerslag op het sociale netwerk, met name als er een gezin is.

De eerste jaren van het strafproces en de periode daarna wordt er vaak nog veel contact onderhouden en meegeleefd. Na verloop van tijd ontstaat echter onvermijdelijk een vervreemding van de buitenwereld en vice versa. Mensen buiten ontwikkelen zich, maken veel mee en leren nieuwe mensen kennen. De gedetineerde verblijft in een kleine, zeer voorspelbare en monotone omgeving, waar doorgaans weinig over te vertellen valt. Het is voor de buitenwereld moeilijk te doorzien hoe het dagelijkse leven in de gevangenis eruit ziet, hetgeen vaak nog versterkt wordt door een neiging van de gedetineerde om zijn dierbaren te beschermen door negatieve zaken te verzwijgen. $\mathrm{Al}$ met al worden contacten steeds oppervlakkiger en ongelijkwaardiger. De gedetineerde komt in de positie van iemand waar voor gezorgd moet worden, afhankelijk van en in zekere zin ook belastend voor zijn omgeving. Deze afhankelijkheid gaat erg ver binnen het Nederlandse systeem: gedetineerden zijn grotendeels afhankelijk van geld van buiten om iets meer dan basale voorzieningen te kunnen kopen en voor zaken als kleding (zelfs 
ondergoed) moet iemand buiten worden ingeschakeld. De rol binnen het sociale systeem (met verantwoordelijkheid, aanzien en invloed, bijvoorbeeld als vader) verzwakt, wat tot frustratie en machteloosheid leidt bij de gedetineerde. Het zelfbeeld wordt aangetast en de gedetineerde probeert vaak druk en controle uit te oefenen om dit tegen te gaan. Een andere veelvoorkomende reactie is somberheid en zich terugtrekken, waardoor contacten verwateren of zelfs verbroken worden.

Overigens moet worden opgemerkt dat, zeker in deze fase, gedetineerden met levenslang paradoxaal genoeg vaak tot een relatief goede aanpassing komen. Naarmate de strijd tegen het systeem (en tegen het vonnis) verder naar de achtergrond verdwijnt, gaat men zich meer verenigen met de inrichting. Uit psychologisch oogpunt is dit te verklaren vanuit de behoefte om toch enige autonomie en eigenwaarde te bewaren: door de normen van de omgeving tot de jouwe te maken kun je zonder innerlijk conflict meewerken. Hoewel er in formeel opzicht weinig te verdienen is met goed gedrag binnen detentie $^{9}$ levert het wel waardering van personeel op, wat zich vaak vertaalt in kleine gunsten zoals een soepele toepassing van regels of het verblijf op een prettige afdeling. In deze fase wordt nogal eens een beroep gedaan op hulpverleners (psycholoog, geestelijk verzorgers) binnen de inrichting, zelfs door gedetineerden die daar eerder niet voor open stonden. Ook in dat opzicht gaat men zich meer naar binnen (de inrichting) richten.

Fase 4 is de periode van hospitalisatie en vervlakking. De buitenwereld verdwijnt steeds meer naar de achtergrond en de gedetineerde raakt vergroeid met (de voorspelbaarheid van) de inrichting. Hoop op gratie of andere vrijheden wordt steeds vluchtiger en men gaat zich afsluiten van de toekomst. Vaak zijn de contacten met de buitenwereld tot een minimum gereduceerd en houdt men zich vooral vast aan enkele vertrouwenspersonen binnen de inrichting. Geestelijk verzorgers (pastor, humanist, imam) of vrijwilligers kunnen in deze fase soms een belangrijke steun zijn, ook al omdat de situatie steeds meer existentiële vragen gaat oproepen. Het verdwijnen van toekomstperspectief leidt tot vragen op het gebied van zingeving en in deze fase komen dan ook geregeld gedachten over suïcide (weer) op. De balans in het dagelijks leven moet worden opgemaakt tussen kleine verworvenheden binnen de inrichting, korte termijn doelen (bijvoorbeeld een

9 In het programma DBM is veel aandacht besteed aan stimuleren en ontmoedigen, maar de middelen voor gedragsbeïnvloeding liggen vooral op het gebied van vrijheden. Het is dus zeer de vraag in hoeverre levenslanggestraften hiervan zullen profiteren. 
bepaald bezoek of een feestdag) en de voortdurende uitzichtloosheid op lange termijn. Voor het gevoel van eigenwaarde is de gedetineerde sterk afhankelijk van steun van personeel of (vaak beperkte) contacten buiten, maar doorgaans is dit evenwicht wankel. Hoe realistischer men naar zijn eigen situatie kijkt, hoe beter men beseft feitelijk weinig te kunnen betekenen voor de ander. Goed functioneren en volhouden wordt dan een doel op zich: in elk geval doe je de mensen die zich om je bekommeren geen extra verdriet. De gedetineerde wordt daardoor ook extra gevoelig voor veranderingen in zijn omgeving, aangezien daarmee de kwetsbare balans wordt verstoord. Het vertrek van een vertrouwd personeelslid of het wegvallen van een activiteit kan als zeer ingrijpend worden ervaren.

\section{Het dilemma voor het gevangeniswezen}

De beschreven effecten uit de vorige paragraaf zijn in feite de natuurlijke uitvloeisels van het systeem van vrijheidsstraffen, waarmee ze in zekere zin onvermijdelijk lijken. Veel van de nadelige effecten die worden geschetst, worden bij gratieverzoeken doorgaans ook op die wijze beoordeeld: bij een (lange) straf hoort nu eenmaal een verminderd contact met familie en een verlies van bepaalde rechten of vrijheden. De rechter zou deze afweging hebben meegenomen in de oplegging van de straf. Toch is deze constatering in mijn ogen te simpel. De opzet van ons gevangeniswezen is namelijk gebaseerd op bepaalde keuzes die wel degelijk verschillend uitpakken voor verschillende gedetineerden. Zo is het uitgangspunt bij het opzetten van dagprogramma's en regimes per definitie de grootste gemene deler en dat is een tijdelijk en relatief kort verblijf in detentie. Daarnaast is er (zeker in de nieuwe plannen van DBM) weliswaar nadrukkelijk aandacht voor het uitzetten van trajecten en resocialisatie, maar tegelijk ook voor efficiency, doelmatigheid en uniformiteit.

Deze keuzes vertalen zich in een stelsel waarin pas in de laatste fase van een straf echt iets te verdienen valt. Voor kortgestraften komt dat vooruitzicht relatief snel: als ze zich goed gedragen komen er trajecten, begeleidingsmogelijkheden en vrijheden. Voor de zeer langgestrafte geldt dit al in beperkte mate (de eerste jaren is er vrijwel niets mogelijk en wordt goed gedrag nauwelijks beloond) maar voor de levenslanggestrafte is deze mogelijkheid ten enenmale uitgesloten. Feitelijk houdt dit in dat de enige 'keuzevrijheid' die de levenslanggestrafte heeft varieert tussen negatief en negatiever. Vrijheden, opleiding, zingeving, ruimer contact met het sociale netwerk: vrijwel 
alles blijft buiten zijn bereik. In dit opzicht is het steeds weer verbazend hoeveel levenslanggestraften toch tot een redelijke aanpassing komen.

\section{Identiteit en zelfbeschikking}

De situatie van de levenslanggestrafte roept vroeger of later existentiële kwesties op rondom zelfbeeld, identiteit en invulling van het leven. Detentie is bij uitstek een situatie van beperkte zelfbeschikking, hetgeen sterker geldt naarmate de detentie langer duurt. Het ondergaan van een zo machteloze en uitzichtloze situatie als een levenslange detentie maakt dat iemand zichzelf anders moet gaan definiëren. Door het langdurig wegnemen van eigen verantwoordelijkheid en eigen keuzes ontstaat stress en na verloop van tijd ook een conflict in het zelfbeeld. Strijd en verzet leveren alleen maar meer negatieve effecten op, zodat men vroeger of later uitgeblust raakt en de strijd opgeeft. Dit lijkt de voornaamste reden voor de 'goede' aanpassing van deze gedetineerden: door mee te geven met het systeem kun je met relatief weinig energie toch nog enige keuzevrijheid creëren. Het paradoxale effect van deze aanpassing is echter dat de levenslanggestrafte daarmee als het ware uit beeld verdwijnt. De stabiele en rustige aanpassing wekt de indruk dat er weinig aan de hand is en maakt dat deze gedetineerden in de inrichting vaak 'tot het meubilair gaan behoren'. De zorg gaat uit naar meer acute en in het oog springende problematiek en de levenslanggestrafte wordt dankzij zijn aanpassing min of meer verwaarloosd.

\section{Hoe zou het anders kunnen?}

Uiteraard is de kern van de problematiek van de levenslange straf niet weg te nemen (het is tenslotte bedoeld als zware straf en voorbehouden aan zeer ernstige zaken) maar er lijkt toch wel verbetering mogelijk. Een belangrijke stap daarin moet de erkenning zijn dat levenslang een bijzondere straf is. Hoewel het een kleine groep betreft, doen levenslanggestraften vanwege hun lange verblijf een groot beroep op de mogelijkheden van het gevangeniswezen. De laatste tijd lijkt er gelukkig meer aandacht te komen voor de levenslange straf, zowel in de media als binnen justitie. Ook de lezingenreeks waarvoor dit artikel werd opgesteld is daarvan een voorbeeld. 
Zoals uit bovenstaande mag blijken is het voor deze gedetineerden vooral van belang dat er ruimte is voor individuele uitzonderingen en dat er binnen het systeem enige keuzevrijheid en perspectief geboden wordt. Enerzijds valt daarbij te denken aan het opzetten van afdelingen of programma's gericht op zeer langdurig (mogelijk oneindig) verblijf, anderzijds aan het aanpassen van het huidige gratiebeleid. Dit laatste is in de praktijk verworden tot een ondoorzichtig systeem van langdurige procedures die feitelijk vooral valse hoop bieden. Nederland is daarmee een uitzondering in Europa, aangezien elders wel vast omschreven gratieprocedures bestaan, inclusief vaste termijnen. Binnen de ontwikkelingen van DBM zouden de gedachten over gedragsbeïnvloeding kunnen worden gebruikt om ook aan deze categorie gedetineerden iets te bieden. Zowel vrijheden als faciliteiten binnen detentie worden in deze plannen persoonsgebonden aangeboden en als middel ingezet om goed gedrag te bewerkstelligen. Met de nodige terughoudendheid zou dit systeem ook toegepast kunnen worden voor levenslanggestraften, bijvoorbeeld door het kunnen verdienen van een gunstige omgeving of op termijn mogelijk zelfs beperkte vrijheden. Uiteraard moet dit geïndividualiseerd worden toegepast, met aandacht voor het aspect van vergelding (het gepleegde delict, mening van OM, belang van slachtoffers) en voor risicotaxatie (gevaar in de toekomst).

\section{Aanbevelingen}

In deze paragraaf wordt getracht de overwegingen en beschreven problematiek te vertalen in een aantal concrete aanbevelingen. Ten eerste betreft het daarbij aspecten van de opzet binnen detentie, ten tweede meer procedurele zaken rondom de rechtspositie en regelgeving.

- Houdt structurele aandacht voor de groep levenslanggestraften, ook na veroordeling.

- Maak binnen Gevangeniswezen afdelingen waar een klimaat bestaat ingericht op langdurig verblijf. Deze afdelingen dienen zich te kenmerken door een maximale bescherming naar buiten maar een optimale vrijheid naar binnen.

- Biedt zingeving binnen een zeer lange detentie door het mogelijk maken van arbeid of andere activiteiten waarin men zich kan ontplooien en zelfwaardering kan opdoen. Te denken valt aan werkzaamheden binnen een inrichting (in de keuken, in schoonmaak of onderhoud) of het verzorgen van een tuin of wat dieren. Ook creati- 
viteit en zelfstudie zijn een goede mogelijkheid om de langdurige monotonie van het verblijf te vullen.

- Zorg dat plaatsing binnen het Gevangeniswezen niet teveel gestandaardiseerd wordt. Het verblijf op een bepaalde afdeling moet niet uitsluitend bepaald worden door de opgelegde straf maar (met name bij lange straffen) afhankelijk zijn van individuele kenmerken en behoeften van de gedetineerde.

- Een vorm van aansluiting bij de long stay-voorziening in de TBS valt te overwegen (zie ook afsluitende opmerkingen). Zowel qua problematiek als qua bejegeningbehoefte zijn er overeenkomsten tussen deze groepen. Meer onderling verkeer zou dan ook voordelen kunnen opleveren. Uiteraard is daarvoor een grondige aanpassing van wetgeving en kaders nodig om rechtsgelijkheid te waarborgen.

- Creëer perspectief door het invoeren van een duidelijke fasering. Een systeem met vaste toetsingsmomenten en heldere criteria zou houvast geven en de mogelijkheid bieden om de detentie zinvoller in te vullen. Hierbij zou in eerste instantie bijvoorbeeld getoetst kunnen worden op interne mogelijkheden binnen gevangeniswezen, maar na verloop van tijd ook op de mogelijkheid van het verlenen van vrijheden of zelfs gratie. Concreet zou gedacht kunnen worden aan een gratiecommissie bij het ministerie van justitie die op een vast moment van de straf (bijvoorbeeld na 15 jaar) in beeld komt. Periodieke herhaling van zo'n toetsing is een logisch vervolg hierop.

\section{Afsluitende opmerkingen}

Het voorgaande is bedoeld als beschrijving van de wijze waarop de huidige tenuitvoerlegging van de levenslange straf in de praktijk uitpakt. Daaromheen zijn echter nog enkele punten die het waard zijn vermeld te worden, maar die buiten het bereik van dit artikel vallen. Het betreft dan met name observaties die te maken hebben met ons stelsel van strafrecht, waarin een strikte scheiding is aangebracht tussen straf en maatregel (of tussen vergelding en behandeling). De keuze tussen deze opties (of voor een combinatie daarvan) wordt gemaakt in het strafproces op basis van een (gedrags-) deskundigenoordeel over toerekeningsvatbaarheid en toekomstig gevaar. De inschatting van de deskundige en het oordeel van de rechter zijn weliswaar grondig onderbouwd, maar blijven tegelijk een momentopname, die kan worden beïnvloed door tijdsbeeld of druk van de media. Naar mijn mening 
zou voortschrijdend inzicht (zowel in de wetenschap als bijvoorbeeld door veranderingen bij de betreffende gedetineerde) moeten kunnen leiden tot aanpassing van de eens ingeslagen route. Uiteraard dienen daarbij alle belangen zeer zorgvuldig te worden afgewogen, zoals de vergelding van slachtoffers, de beveiliging van de maatschappij en het belang van de gedetineerde.

In de dagelijkse praktijk van de tenuitvoerlegging bestaat soms de indruk dat de keuze van de rechter tussen levenslang, een tijdelijke straf of een combinatievonnis (straf en TBS) moeilijk te voorspellen is en niet vrij lijkt van subjectieve of willekeurige factoren. De keuze bepaalt echter in zeer sterke mate het toekomstperspectief van de betreffende gedetineerde (en soms ook de veiligheid van de maatschappij), terwijl er niet meer gecorrigeerd kan worden. Immers, de toepassing van art. 41 PM (plaatsing van een tot gevangenisstraf veroordeelde in een TBS-inrichting) is in de praktijk net zo'n 'dode letter' als gratie: het wordt vrijwel nooit toegekend. Dit houdt in dat een gedetineerde aan wie geen TBS is verleend feitelijk alleen behandeld kan worden op vrijwillige basis en in de fase van de straf waarin vrijheden mogelijk zijn. Een behandeling wordt daarmee per definitie beperkt in de tijd en sterk afhankelijk van de eigen motivatie van de gedetineerde. Ook hier geldt dat de levenslanggestrafte helemaal is uitgesloten van deze mogelijkheid. ${ }^{10}$ Het zou dan ook te wensen zijn dat er in de toekomst een flexibeler systeem ontstaat waarin grensverkeer tussen beide sectoren (gevangeniswezen en TBS) eenvoudiger wordt en dat het gratiestelsel aan herziening wordt onderworpen. Naar mijn mening zouden zowel de veiligheid van de maatschappij als de doelmatigheid van ons sanctiestelsel daarbij gebaat zijn.

10 Met uitzondering van een tijdelijke plaatsing in een gesloten forensische kliniek bij acute crisissituaties, zoals ernstige suïcidaliteit. 